\title{
Gemcitabine-associated thrombotic microangiopathy in a patient with lung cancer: A case report
}

\author{
FLORENCE LAI-TIONG $^{1 *}$, YANN DUVAL $^{1 *}$ and FRANCOIS KRABANSKY ${ }^{2}$ \\ ${ }^{1}$ Jean Godinot Institute; ${ }^{2}$ Department of Pharmacovigilance and Pharmacoepidemiology, \\ Reims University Hospital, 51100 Reims, France
}

Received April 1, 2015; Accepted May 16, 2016

DOI: $10.3892 / \mathrm{ol} .2017 .5576$

\begin{abstract}
Gemcitabine is frequently used for the treatment of a number of different cancer types. Gemcitabine-related thrombotic microangiopathy (TMA) has rarely been described, but it is a life-threatening complication. The incidence of the complication varies between 0.015 and $1.4 \%$. The present study reports the case of a 63-year-old Caucasian male who was treated with 3 cycles of carboplatin plus gemcitabine, followed by 7 cycles of gemcitabine only, and developed clinical symptoms that, together with laboratory findings, were compatible with a diagnosis of hemolytic uremic syndrome TMA. The patient was admitted to Jean Godinot Cancer Center Institute with hemolysis, thrombocytopenia, macroscopic hematuria, renal dysfunction and worsening high blood pressure. Medical treatment for the high blood pressure, plasma infusion and hemodialysis were implemented without any improvement in creatine levels. The patient recovered from hematological disorders, left hospital and was followed-up. He required hemodialysis until he succumbed $\sim 3$ months subsequent to diagnosis of TMA. Even if thrombocytopenia, anemia and renal failure are common observations in patients treated by chemotherapy, clinicians should be aware of this potentially lethal complication. We recommend screening for TMA in such cases of anemia, thrombocytopenia and renal failure.
\end{abstract}

\section{Case report}

A 63-year-old Caucasian male without a previous medical history was diagnosed with metastatic non small cell lung cancer (NSCLC) in March 2013 at Jean Godinot Cancer Center Institute (Reims, France). The patient received first-line treatment with gemcitabine $\left(1,250 \mathrm{mg} / \mathrm{m}^{2}\right)$ plus carboplatin ( $700 \mathrm{mg} / \mathrm{m}^{2}$; area under the curve, 5) every 3 weeks for 3 cycles

Correspondence to: Miss. Florence Lai-Tiong, Jean Godinot Institute, 1 Rue du Général Kœnig, 51100 Reims, France

E-mail: florence.lai-tiongfofo@laposte.net

*Contributed equally

Key words: gemcitabine, thrombotic microangiopathy, lung cancer (overall $\sim 2$ months), followed by 7 cycles of gemcitabine alone (1,000 $\mathrm{mg} / \mathrm{m}^{2}$; day 1 and day 8; overall $\sim 2$ months). Following the seventh cycle, the patient developed high blood pressure $(180 / 100 \mathrm{mmHg})$ and was subsequently intravenously administered with enalapril-hydrochlorothiazide $\left(1,000 \mathrm{mg} / \mathrm{m}^{2}\right.$; $1,075 \mathrm{mg} / 30 \mathrm{~min})$.

A week later the patient was admitted to Jean Godinot Cancer Center due to acute renal failure. The patient's serum creatinine level had reached $199 \mu \mathrm{mol} / \mathrm{l}$ (normal range, $65-120 \mu \mathrm{mol} / \mathrm{l})$, the platelet level was decreased to $17 \times 10^{9} / 1$ (normal range, 150-400x10 $/ 1$ ) and the hemoglobin level was decreased to $8.3 \mathrm{~g} / \mathrm{dl}$ (normal range, 129-167 g/l). Ultrasound of the urinary tract did not show any signs of obstruction and a urine test did not reveal a functional profile.

Further investigations revealed a normal coagulation pattern, with a bilirubin level of $47 \mu \mathrm{mol} / 1$ (normal range, 3.4-17 $\mu \mathrm{mol} / \mathrm{l}$ ), a lactose dehydrogenase (LDH) level of 2,374 IU/1 (normal range, 200-450 IU/1), reticulocytes at 7.5\% (normal range, 1-2.5\%) and an undetectable haptoglobin level ( $<0.10 \mathrm{~g} / \mathrm{l}$; normal range, 0.5-2.5 g/l). Schiztocytes were found on the peripheral blood smear. Albuminemia (35.4 g/l; normal range, $35-50 \mathrm{~g} / \mathrm{l}$ ) and proteinuria (4.21 g per day; $3.51 \mathrm{~g} / \mathrm{l}$; normal range, $<150 \mathrm{mg}$ per day ot $<0.20 \mathrm{~g} / \mathrm{l}$ ) were noted, in association with macroscopic hematuria. Complement factors were within normal ranges. A disintegrin and metalloproteinase with thrombospondin motifs 13 (ADAMTS13) activity was also normal.

Thrombotic microangiopathy (TMA) was suspected and this diagnosis of hemolytic uremic syndrome (HUS) TMA was later confirmed by renal biopsy.

The patient received two infusions of three units each of freshly frozen plasma. Also, patient stabilization required three units of packed red cells. Blood pressure was controlled using multiple antihypertensive medications $(80 \mathrm{mg}$ furosemide, intravenous nicardipine and $5 \mathrm{mg}$ beta blockers twice a day). At day 16 post-presentation, hemodialysis was started.

The patient recovered quickly from the thrombopenia and anemia. However, renal failure persisted and the patient required hemodialysis until he succumbed $\sim 3$ months subsequent to the diagnosis of TMA.

\section{Discussion}

TMA is a disorder characterized by microvascular occlusion due to platelet aggregation, thrombocytopenia and organ 
damage, such as renal failure (1). The main subtypes of TMA are HUS and thrombotic thrombocytopenic purpura (TTP). Thrombocytopenia, schistocytosis and elevated levels of $\mathrm{LDH}$ are enough to form a diagnosis in clinical practice. The majority of cases are idiopathic, but several etiologies have been recognized, among which are the use of cytotoxic chemotherapies, including mitomycin $\mathrm{C}$, bleomycin, cisplatin and 5-fluorouracil (2). TMA may also be caused by the underlying malignancy itself $(3,4)$. Indeed, TMA associated with metastatic adenocarcinomas, such as those of the stomach, colorectum, breasts, lungs and prostate, have been reported (5-7). It can be difficult to distinguish between HUS caused by the cancer itself and that caused by the chemotherapy. Certain studies have suggested that malignancy-associated HUS typically occurs during widespread metastatic disease, whereas the chemotherapy-associated type occurs more frequently when the patient is in disease remission. In the present study, the patient had minimal tumor burden.

The physiopathology of this disease remains unclear. Several mechanisms have been suggested, including an immune-mediated response or a direct toxic effect. Endothelial injury is the main event (8). HUS does not appear to be associated with a deficiency in ADAMTS13 activity; indeed, even if ADAMTS13 activity is absent or deficient in familial TTP, this condition it is not sufficient to cause the syndrome. Also, no specific correlation has been found between TMA and gender or age (9).

ADAMTS13 has been shown to be of major pathophysiological importance TMA in the setting of TTP when either lacking antibodies against ADAMTS13 (inherited TTP) or if antibodies against ADAMTS13 are present (acquired TTP). A severe deficiency of $<5 \%$ ADAMTS-1 activity, with clinical symptoms of an acute thrombocytopenia and evidence of a microangiopathic hemolytic anemia, appropriately defines a diagnosis of TTP $(10,11)$.

Gemcitabine is an important chemotherapeutic agent and its indications in oncology and hematology are wide. It is used in the therapy of pancreatic, ovarian, breast and bladder cancers, and NSCLC. Gemcitabine is associated with side effects that can lead to patient mortality (9).

First-line gemcitabine combined with cisplatin is indicated in patients with inoperable NSCLC (locally advanced or metastatic). In 1994, the first case of gemcitabine-associated TMA occurred during a phase II trial in pancreatic metastatic adenocarcinoma (12). To the best of our knowledge, there have been only 3 cases of gemcitabine-associated microangiopathy in patients treated for NSCLC to date (6).

The incidence of gemcitabine-attributed TMA is between 0.015 and $1.4 \%$ (13). However, the true incidence is difficult establish due to its underreported nature, the poor recognition of the condition or the failure to diagnose mild symptoms (14). A TMA diagnosis is more difficult in patients treated for cancer compared with otherwise healthy individuals, as certain symptoms may be adverse effects of chemotherapy agents. Clinically, TTP presents with hemolytic anemia, thrombocytopenia and renal insufficiency. Neurological symptoms and a fever are often present. However, anemia and thrombocytopenia are also common side-effects associated with chemotherapy due to myelotoxicity. Data on the incidence of TMA associated with gemcitabine use are conflicting.
In 2004, in a study by Humphreys et al (15), the incidence of gemcitabine-associated TMA was shown to be $0.31 \%$. This was in contrast with the estimated incidence of only $0.015 \%$ described by Fung et al in 1999 (16). In Boston, a review was performed between 1997 and 2002, and among 2,586 patients, 9 were identified with gemcitabine-associated TMA (15). New or exacerbated hypertension preceded the diagnosis of TMA by $0.5-10$ weeks. The study concluded that this could represent an early clinical marker for the presence of a TMA syndrome (8). In the present study, the blood pressure of the patient remained high at 200/110 $\mathrm{mmHg}$ for several days.

The risk for gemcitabine-associated TMA appears to increase with a cumulative drug dose of $>20,000 \mathrm{mg} / \mathrm{m}^{2}$ or administration for $>18$ cycles (14). The condition rarely occurs prior to 7 months of therapy. In the present case, the patient received only $10,750 \mathrm{mg} / \mathrm{m}^{2}$ (cumulative dose) of gemcitabine during 8 months. In the majority of reported cases, gemcitabine has been administered as a single-agent treatment, but in other cases, such as the present study, the condition has been reported during combination therapy (16). Screening for TMA has been proposed for after 10 cycles of gemcitabine. However, the development of TTP has been also reported after a single dose of gemcitabine (17).

A number of different treatments types have been previously suggested for patients with HUS $(7,18)$. Glucocorticoids and plasma infusion may be used, but the interruption of chemotherapy and plasma exchange are the mainstays of treatment, and these therapies are quite effective. Management also involves the control of hypertension. Although these treatments are readily available, HUS remains a highly fatal disease.

The estimated mortality rate for HUS is $10-40 \%$ in the majority of case series $(19,20)$, but has been reported to be as high as $60-70 \%$ in others $(7,21,22)$.

Humphreys et al (15) recommend that for patients receiving gemcitabine for $>3$ months, the creatinine, schistocyte and haptoglobin levels should be checked monthly. Desramé et al (23) proposed that systematic screening should be performed for HUS during gemcitabine therapy. In this series, the frequency of HUS was $2.2 \%$.

In conclusion, even if TMA is a rare adverse effect of cancer therapy, clinicians should be aware of it due to its potentially lethal evolution. Chemotherapy-induced TMA and that caused by the cancer itself are difficult to differentiate between, but the patient's clinical data can aid the clinician in making the right diagnosis. The precise and regular reporting of chemotherapeutic adverse events may assist in evaluating the frequency of TMA. Although no precise recommendation exists for the diagnosis and treatment of TMA, we suggest that chemotherapy should be halted and a glucocorticoid therapy or a plasma infusion should be introduced. Any worsening of anemia, thrombocytopenia or serum creatinine level with high blood pressure should lead to a prompt examination.

\section{References}

1. Symmers WS: Thrombotic microangiopathic haemolytic anaemia (thrombotic microangiopathy). Br Med J 2: 897-903, 1952.

2. Anai H, Okada Y, Okubo K, Korenaga D, Maehara Y, Sugimachi K and Ohi Y: A case report of hemolytic uremic syndrome (HUS) induced by antineoplastic agents. Nihon Gan Chiryo Gakkai Shi 25: 1487-1491, 1990 (In Japanese). 
3. Schjølseth SA, Hagen T, Ottestad L and Jakobsen E: Chemotherapy-induced hemolytic uremic syndrome. A complication to mitomycin treatment of breast carcinoma. Tidsskr Nor Laegeforen 115: 3371-3373, 1995 (In Norwegian).

4. Seo DW, Lee YS, Chae JG, Lee MG, Choe GY, Chi HS and Min YI: Hepatocellular carcinoma associated hemolytic uremic syndrome unrelated to chemotherapy. J Korean Med Sci 9: 254-258, 1994.

5. Murgo AJ: Cancer- and chemotherapy-associated thrombotic microangiopathy. In: Hemolytic-Uremic Syndrome and Thrombotic Thrombocytopenic Purpura. Kaplan BS, Trompeter RS and Moake JL (eds). Marcel Dekker, New York, NY, pp271-285, 1992.

6. Pisoni R, Ruggenenti P and Remuzzi G: Drug-induced thrombotic microangiopathy: Incidence, prevention and management. Drug Saf 24: 491-501, 2001.

7. Lesesne JB, Rothschild N, Erickson B, Korec S, Sisk R, Keller J, Arbus M, Woolley PV, Chiazze L and Schein PS: Cancer-associated hemolytic-uremic syndrome: Analysis of 85 cases from a national registry. J Clin Oncol 7: 781-789, 1989.

8. Hillyer CD, Duncan A, Ledford M, Barrett TJ, Klumpp SA, Anderson DC, McClure HM and Winton EF: Chemotherapy-induced hemolytic uremic syndrome: Description of a potential animal model. J Med Primatol 24: 68-73, 1995.

9. Feys HB, Roodt J, Vandeputte N, Pareyn I, Lamprecht S, van Rensburg WJ, Anderson PJ, Budde U, Louw VJ, Badenhorst PN et al: Thrombotic thrombocytopenic purpura directly linked with ADAMTS13 inhibition in the baboon (Papio ursinus). Blood 116: 2005-2010, 2010

10. Lichtman LA, Beutler E, Kipps TJ, Seligsohn U, Kaushansky K and Prchal JT (eds): Williams Hematology. 7th edition. Sydney: McGraw-Hill Medical, Sydney, 2006.

11. Tsai HM: The molecular biology of thrombotic microangiopathy. Kidney Int 70: 16, 2006.

12. Casper ES, Green MR, Kelsen DP, Heelan RT, Brown TD Flombaum CD, Trochanowski B and Tarassoff PG: Phase II trial of gemcitabine (2,2'-difluorodeoxycytidine) in patients with adenocarcinoma of the pancreas. Invest New Drugs 12: 29-34, 1994.
13. Oberic L, Buffet M, Schwarzinger M, Veyradier A, Clabault K, Malot S, Schleinitz N, Valla D, Galicier L, Bengrine-Lefèvre L, et al: Cancer awareness in atypical thrombotic microangiopathies. Oncologist 14: 769-779, 2009.

14. Walter RB, Joerger M and Pestalozzi BC: Gemcitabine-associated hemolytic-uremic syndrome. Am J Kidney Dis 40: E16, 2002.

15. Humphreys BD, Sharman JP, Henderson JM, Clark JW, Marks PW, Rennke HG, Zhu AX and Magee CC: Gemcitabine-associated thrombotic microangiopathy. Cancer 100: 2664-2670, 2004.

16. Fung MC, Storniolo AM, Nguyen B, Arning M, Brookfield W and Vigil J: A review of hemolytic uremic syndrome in patients treated with gemcitabine therapy. Cancer 85: 2023-2032, 1999.

17. De Smet D, Jochmans K and Neyns B: Development of thrombotic thrombocytopenic purpura after a single dose of gemcitabine. Ann Hematol 87: 495-496, 2008.

18. Sedlacek SM: First-line and salvage therapy of metastatic breast cancer with mitomycin/vinblastine. Oncology 50 (Suppl 1): S16-S21, 1993.

19. Hollenbeck M, Kutkuhn B, Aul C, Leschke M, Willers R and Grabensee B: Haemolytic-uraemic syndrome and thrombotic-thrombocytopenic purpura in adults: Clinical findings and prognostic factors for death and end-stage renal disease. Nephrol Dial Transplant 13: 76-81, 1998.

20. Sens YA, Miorin LA, Silva HG, Malheiros DM, Filho DM and Jabur P: Acute renal failure due to hemolytic uremic syndrome in adult patients. Ren Fail 19: 279-282, 1997.

21. Sheldon R and Slaughter D: A syndrome of microangiopathic hemolytic anemia, renal impairment, and pulmonary edema in chemotherapy-treated patients with adenocarcinoma. Cancer 58: 1428-1436, 1986.

22. Mergenthaler HG, Binsack T and Wilmanns W: Carcinoma-associated hemolytic-uremic syndrome in a patient receiving 5-fluorouracil-adriamycin-mitomycin $\mathrm{C}$ combination chemotherapy. Oncology 45: 11-14, 1988.

23. Desramé J, Duvic C, Bredin C, Béchade D, Artru P, Brézault C, Defuentes G, Poirier JM, Dourthe LM, Coutant G, et al: Hemolytic uremic syndrome as a complication of gemcitabine treatment: Report of six cases and review of the literature. Rev Med Interne 26: 179-188, 2005 (In French). 